\title{
Molecular phylogeny of the land snail genus Alopia (Gastropoda: Clausiliidae) reveals multiple inversions of chirality
}

\author{
ZOLTÁN FEHÉR ${ }^{1}$, LÁSZLÓ NÉMETH² ${ }^{2}$ ALEXANDRU NICOARĂ ${ }^{3}$ and \\ MIKLÓS SZEKERES ${ }^{4 *}$ \\ ${ }^{1}$ Department of Zoology, Hungarian Natural History Museum, Baross u. 13, H-1088 Budapest, \\ Hungary \\ 11 2@-, Rekettye u. 24, H-1155 Budapest, Hungary \\ ${ }^{3}$ Department of Ecology and Environmental Protection, Lucian Blaga University, Str. Oituz 31, \\ R-550337 Sibiu, Romania \\ ${ }^{4}$ Institute of Plant Biology, Biological Research Centre of the Hungarian Academy of Sciences, \\ Temesvári krt. 62, H-6726 Szeged, Hungary
}

Received 31 July 2012; revised 4 November 2012; accepted for publication 15 November 2012

\begin{abstract}
Whereas the vast majority of gastropods possess dextral shell and body organization, members of the Clausiliidae family are almost exclusively sinistral. Within this group a unique feature of the alpine genus Alopia is the comparable representation of sinistral and dextral taxa, and the existence of enantiomorph taxon pairs that appear to differ only in their chirality. We carried out a molecular phylogenetic study, using mitochondrial cytochrome $c$ oxidase subunit I (COI) gene sequences, in order to find out whether chiral inversions are more frequent in this genus than in other genera of land snails. Our results revealed multiple independent inversions in the evolutionary history of Alopia and a close genetic relationship between members of the enantiomorph pairs. The inferred COI phylogeny also provided valuable clues for the taxonomic division and zoogeographical evaluation of Alopia species. The high number of inverse forms indicates unstable fixation of the coiling direction. This deficiency and the availability of enantiomorph pairs may make Alopia species attractive experimental models for genetic studies aimed at elucidating the molecular basis of chiral stability.
\end{abstract}

(C) 2012 The Linnean Society of London, Zoological Journal of the Linnean Society, 2012 doi: $10.1111 /$ zoj.12002

ADDITIONAL KEYWORDS: Alopia - chirality - Clausiliidae - enantiomorph - Mollusca - phylogeny speciation.

\section{INTRODUCTION}

In contrast to the predominantly bilateral symmetry of most animals, snails develop in an asymmetric fashion, which is easily recognizable by the helical organization of their body. The vast majority of taxa display dextral chirality, characterized by the clockwise growth of the shell when viewed from its apex. Rare mutant populations of opposite, sinistral coiling

*Corresponding author. E-mail: szekeres@brc.hu have proven instrumental for investigating the molecular genetic background of chiral determination. These studies revealed that coil direction depends on the polar orientation of cells at the early embryonic stage, which is established by the correct performance of polarity-setting cytoskeletal elements (Crampton, 1894; Shibazaki, Shimizu \& Kuroda, 2004; Kuroda et al., 2009). Although the key function determining chirality has not yet been identified, genetic studies in species of four gastropod superfamilies indicated that it is a maternally inherited dominant cytoplasmic factor encoded by a single gene 
(Sturtevant, 1923; Degner, 1952; Asami, Gittenberger \& Falkner, 2008). Mutations in this gene can have considerable evolutionary consequences. For instance,

2 altered body structure can make inverse individuals less likely targets for predation (Hoso, Asami \& Hori, 2007), and severely reduced mating success with noninverted members of the population can lead to reproductive isolation (Gittenberger, 1988). These effects can enhance diversification and lead to the appearance of new subspecies and species.

Despite the ancestral dominance of dextrality in gastropods, sinistral coiling can be found at various taxonomic levels. In dextral species there are several reports of rare inverted individuals, as well as of small populations with frequent or uniform sinistrality. Also, there are entire species, genera, and even families of gastropods with dominant sinistrality (for examples, see Davison et al., 2005). One of the sinistral families is that of the clausiliids (Clausili- idae, door snails), characterized by a spindle-shaped shell that is equipped with intricate closing (clausiliar) apparatus. Situated inside the last whorl, this structure efficiently seals the entrance when the snail retreats, and consists of multiple lamellae and plicae that are useful morphological markers for taxonomists. Sinistrality is very stringently determined in most clausiliid subfamilies, but not in the relatively young and species-rich Alopiinae that dominate the eastern Mediterranean basin. In this subfamily a number of genera also include dextral species (Gittenberger \& Uit de Weerd, 2006; Nordsieck, 2007).

Among the Alopiinae genera that include dextral species, Alopia H. \& A. Adams, 1855, a south-east European genus endemic to the Carpathian Mountains (Fig. 1), is of particular interest. In contrast to the other genera composed of predominantly sinistral species, in this genus sinistral and dextral forms are represented comparably, with 50 and 23 taxa,

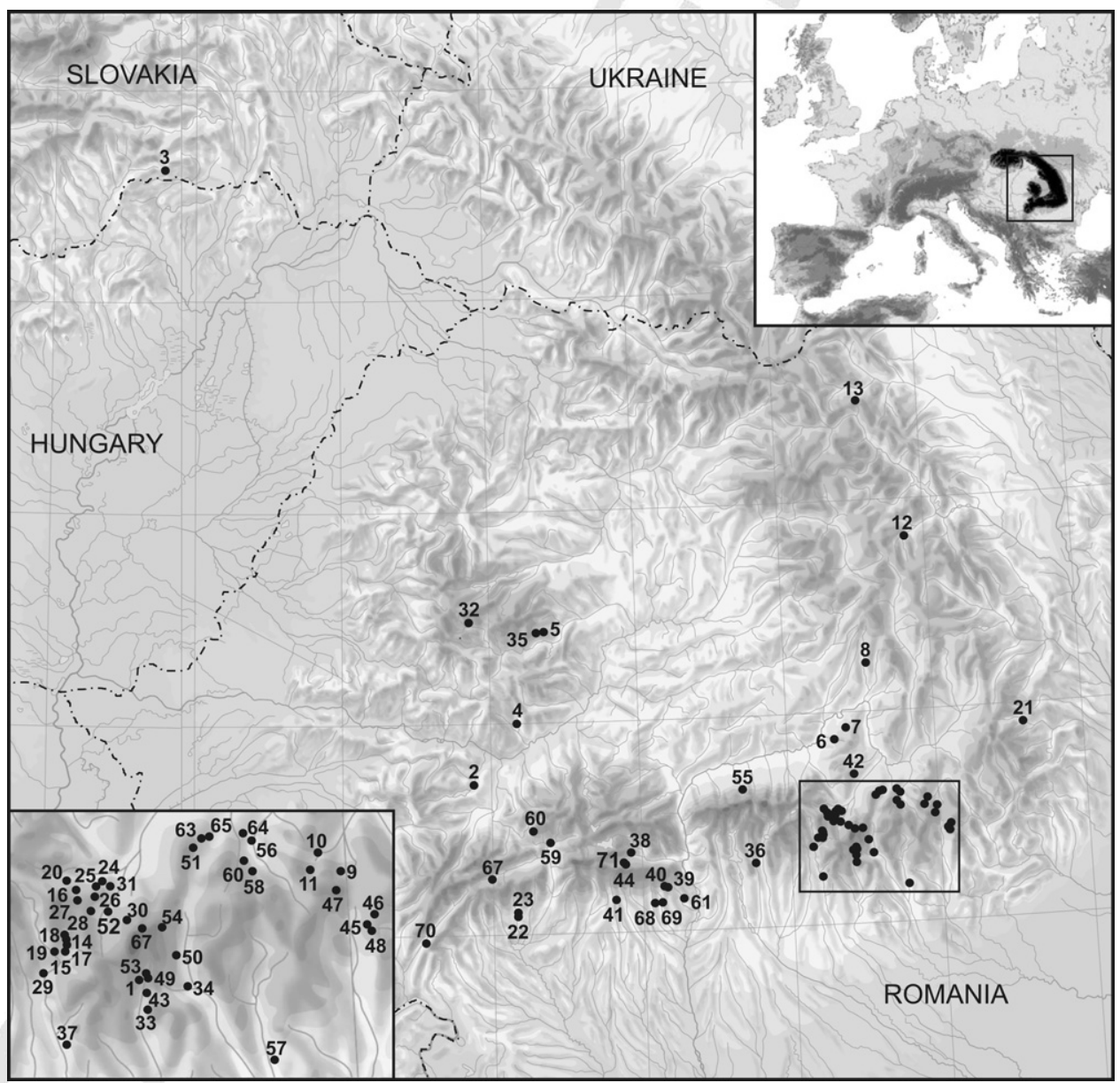

Figure 1. Sampling sites of the Alopia material studied from the Romanian and Slovakian Carpathians. The taxa and localities corresponding to the numbered dots are identified in Table 1. The insets show the position of the Carpathians (black shaded) in Europe and an enlarged map of the south-eastern Carpathian ranges (upper right and lower left corners, respectively). 
respectively. Furthermore, Alopia includes enantiomorph (oppositely coiled, but otherwise seemingly identical) taxon pairs that always occur in contiguous ranges (Wagner, 1914; Soós, 1943). Considering that in other clausiliid genera chiral inversions are very rare, the null hypothesis of our current study was that Alopia is not an exception from this rule. In this case the unusually high number of dextral forms might be explained by a reversion that happened early during Alopia diversification, and then served as a basis for a monophyletic lineage of dextral species. The alternative hypothesis was that the dextral taxa of Alopia could have resulted from multiple independent reversion events. Clarifying which of these hypotheses was correct promised intriguing information in broader contexts. If dextral and sinistral lineages evolved in parallel, enantiomorph pairs would exemplify extreme morphological convergence. If, however, the phylogenetic history of the genus included multiple inversions, then the genetic determination of chirality is less stable than in other genera, offering Alopia species as uniquely suitable objects for studying the genetic background of chiral stability. Either way, ascertaining the phylogenies of sinistral and dextral forms could also provide important phylogenetic background for Alopia taxonomy.

As are most genera of the Alopiinae, Alopia is an obligate rock-dwelling genus with numerous, mostly polytypic, species (Nordsieck, 2007). Because of the restricted vagility of the animals and the scattered distribution of their preferred habitat type (bare limestone outcrops), Alopia populations occur in welldefined, isolated patches. Populations of shared morphological characters and geographical ranges have traditionally been considered as subspecies, and currently there is wide consensus regarding their delimitations (Szekeres, 1976; Grossu, 1981; Nordsieck, 2008). However, the evaluation of taxonomic relationships between these subspecies, and particularly the enantiomorph pairs, has long been controversial because of a disagreement over the homologous or homoplastic origin of the dextral subspecies. One attempt at classification was based on the notion that the far-reaching similarity of enantiomorphs, regardless of chirality, indicated close evolutionary relationships, and that classification should rely primarily on other morphological characters of the shells (e.g. sculpture or closing apparatus) and soft organs (e.g. genitalia), rather than chiral differences (Bielz, 1861; Wagner, 1914). Accordingly, these authors regarded enantiomorph pairs as subspecies of the same species. The other, contrasting approach assumed the parallel evolution of sinistral and dextral lineages from the onset of Alopia diversification, concluding that taxa of opposite chirality cannot be classified within the same species (Kimakowicz, 1894). Later systematic studies merely followed up these two classification concepts, favouring either the former (Soós, 1943; Szekeres, 2007) or latter (Soós, 1928; Grossu, 1981; Nordsieck, 2008) approach. Therefore, finding out which of the two concurring approaches faithfully reflects the evolutionary relationships within the genus necessitated ascertaining the phylogenetic origin of dextrality.

The aim of this study was to test our hypotheses on the incidence of chiral inversions by elucidating the evolutionary relationships within Alopia, especially those of the enantiomorph taxon pairs, based on a molecular phylogenetic analysis. The gene sequence best suited for this purpose is mitochondrial cytochrome $c$ oxidase subunit I (COI), because its high divergence rate (Pons et al., 2010) offers good resolution, even at the infraspecific level, it has been successfully used for inferring close phylogenetic relationships in other genera of the Alopiinae (Uit de Weerd, Schneider \& Gittenberger, 2005 and Uit de Weerd, Schneider \& Gittenberger, 2009), and has been proposed to serve as the central barcoding marker for the identification of animal taxa (Hebert et al., 2003). Considering COI data as indicators of genetic divergence, we propose a taxonomic division of the genus that is compatible with both the molecular and morphological characters. Relying on our phylogenetic results we discuss the zoogeographical background of Alopia diversification, and make an attempt at estimating the start date of this process.

\section{MATERIAL AND METHODS}

\section{SNAIL SAMPLES}

The Alopia samples used in this study were collected from the entire geographical range of the genus (Fig. 1; Table 1). Sampling was designed to include most (64) of the 73 recognized taxa, and all those of disputed species affiliations. In order to avoid ambiguous identification, each taxon was sampled at its type locality or one of its localities well known in the literature. Further clausiliid samples of the subfamilies Alopiinae ŁHerilla ziegleri dacica (Pfeiffer, 1852)] and Clausiliinae [Vestia elata (Rossmässler, 1836)] were used as out-groups. The list of samples, with full names and locality information, are given in Table 1. All material, preserved in 99\% ethanol, has been deposited at the Mollusca Collection of the Hungarian Natural History Museum, Budapest (for collection numbers see the GenBank records listed in Table 1).

\section{DNA ISOLATION AND SEQUENCING}

DNA was prepared from foot tissue of ethanolpreserved specimens using QIAamp DNA Mini Kit (Qiagen, Valencia, CA, USA). A 655-bp segment of the 


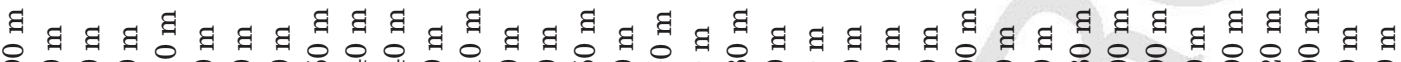

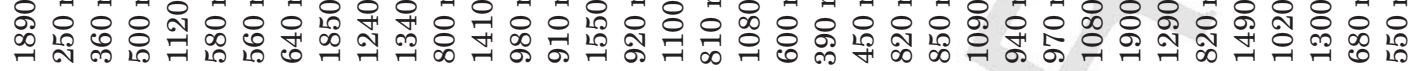

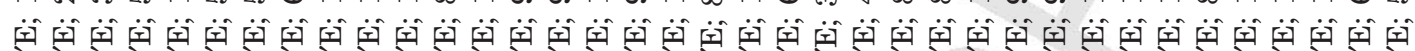

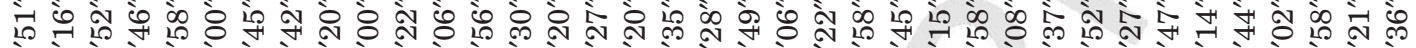

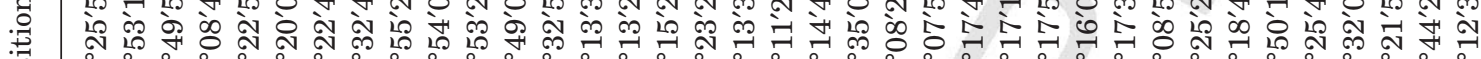

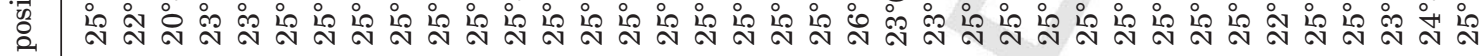

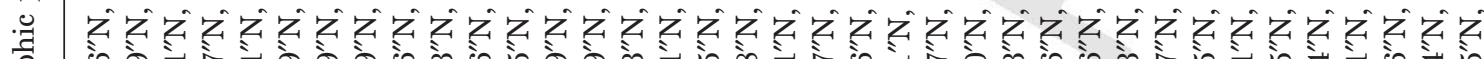

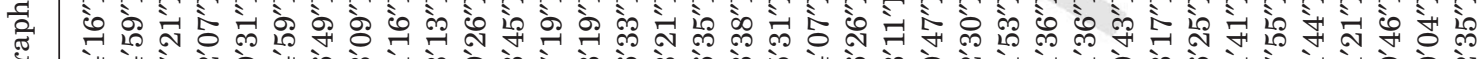

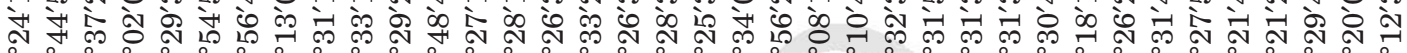

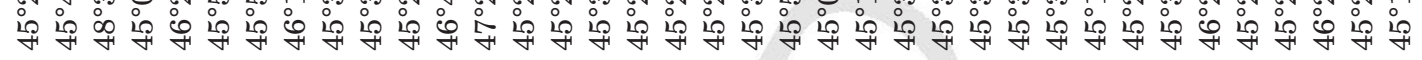
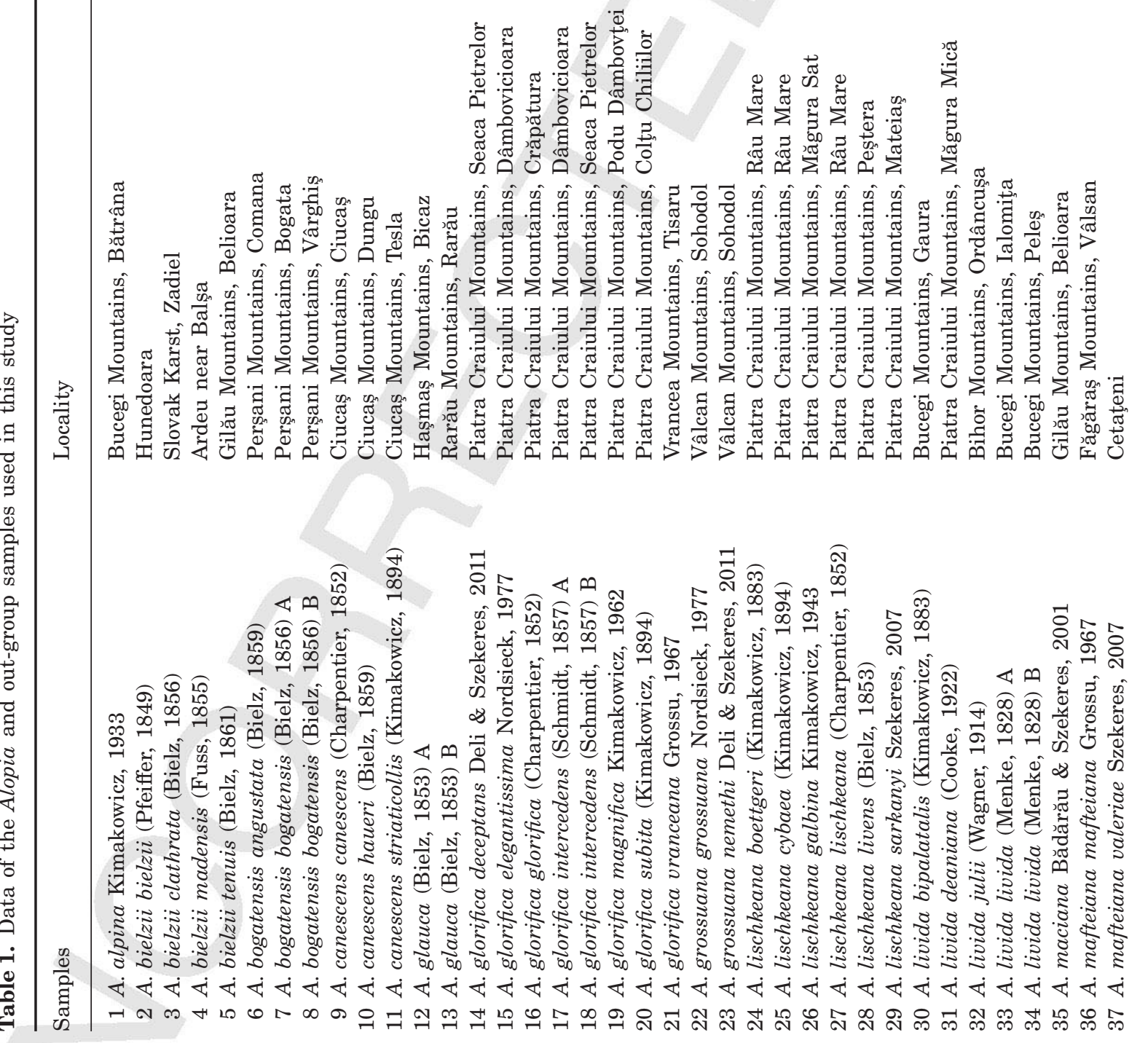

(C) 2012 The Linnean Society of London, Zoological Journal of the Linnean Society, 2012 


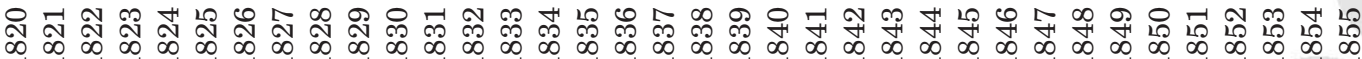

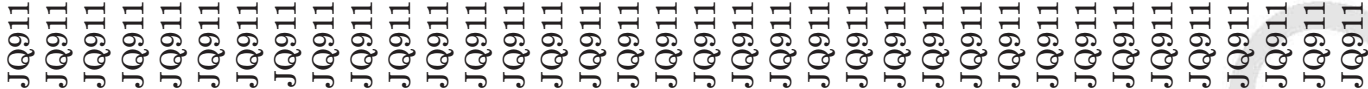

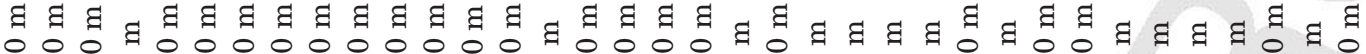

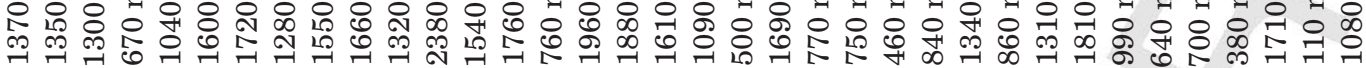

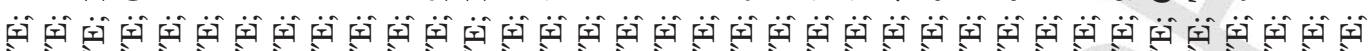
곡

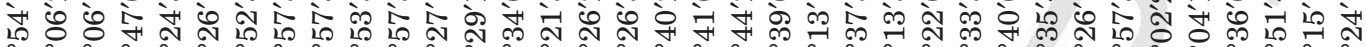

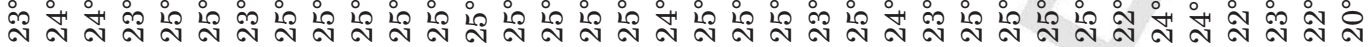

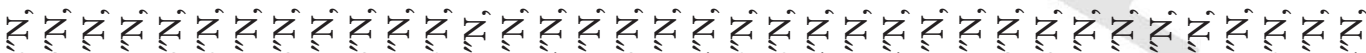
क के ஸิ

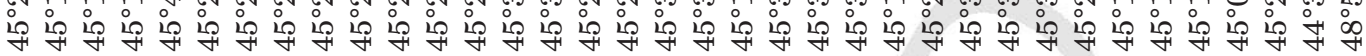
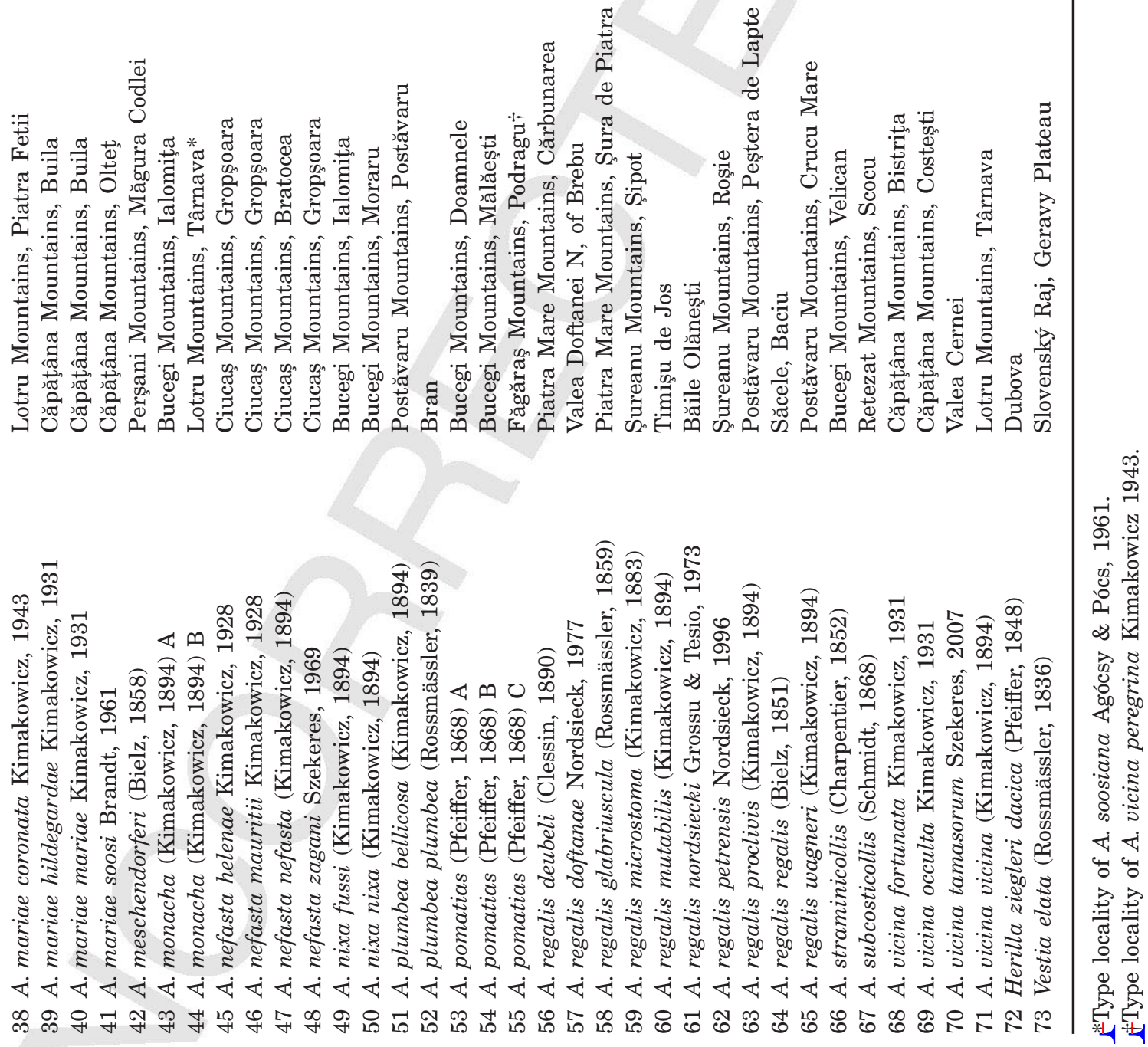
COI gene, between nucleotides 39 and 693 relative to 6 the translational start codon (Hatzoglou, Rodakis \&

7 Lecanidou, 1995), was amplified by polymerase chain reaction (PCR) as described in Fehér et al. (2009). Primers PF372 5'-TCAACGAATCATAAAGATATTGG$3^{\prime}$ and PR373 5'-TATACTTCAGGATGACCAAAGAA TCA-3' were designed by modifying the Albinaria primers L1490-Alb and H2198-Alb (Gittenberger, Piel \& Groenenberg, 2004), respectively. Isolated and purified PCR products were sequenced on both DNA strands using an ABI Prism 3100 Genetic Analyzer (Applied Biosystems, Carlsbad, CA, USA).

\section{PHYLOGENETIC ANALYSIS}

DNA sequences were of equal length (655 bp) and showed proper open reading frames (ORFs), allowing unambiguous alignment. Identical sequences were collapsed into haplotypes. All sequence data have been deposited in GenBank (accession numbers JQ911783-JQ911855; Table 1).
The appropriate model for nucleotide substitution $(\mathrm{HKY}+\mathrm{I}+\mathrm{G})$ was selected by jModelTest 0.1.1 (Guindon \& Gascuel, 2003; Posada, 2008) using the Bayesian Information Criterion (BIC). The invertebrate mitochondrial code table, as implemented in MEGA 5.0 (Tamura et al., 2011), was used to deduce encoded amino acid sequences.

The molecular clock hypothesis was tested by likelihood ratio test in MEGA 5.0, using the topology shown in Figure 2, and the null hypothesis of equal evolutionary rate throughout the tree was rejected $\left(\log L_{0}=-4582.32, \log L_{1}=4665.43\right.$, $\Delta=166.22$, d.f. $=67, P<0.000)$.

Haplotypes were analysed by various methods and settings in order to test the method dependence of phylogenetic tree topology and root position. An unconstrained Bayesian tree was inferred by MrBayes 3.2.1 (Ronquist et al., 2012) using the following parameters: $\mathrm{HKY}+\mathrm{I}+\mathrm{G}$ model of sequence evolution; a four-chain (one cold, three heated; $T=0.2$ ) Metropolis-coupled Markov chain Monte

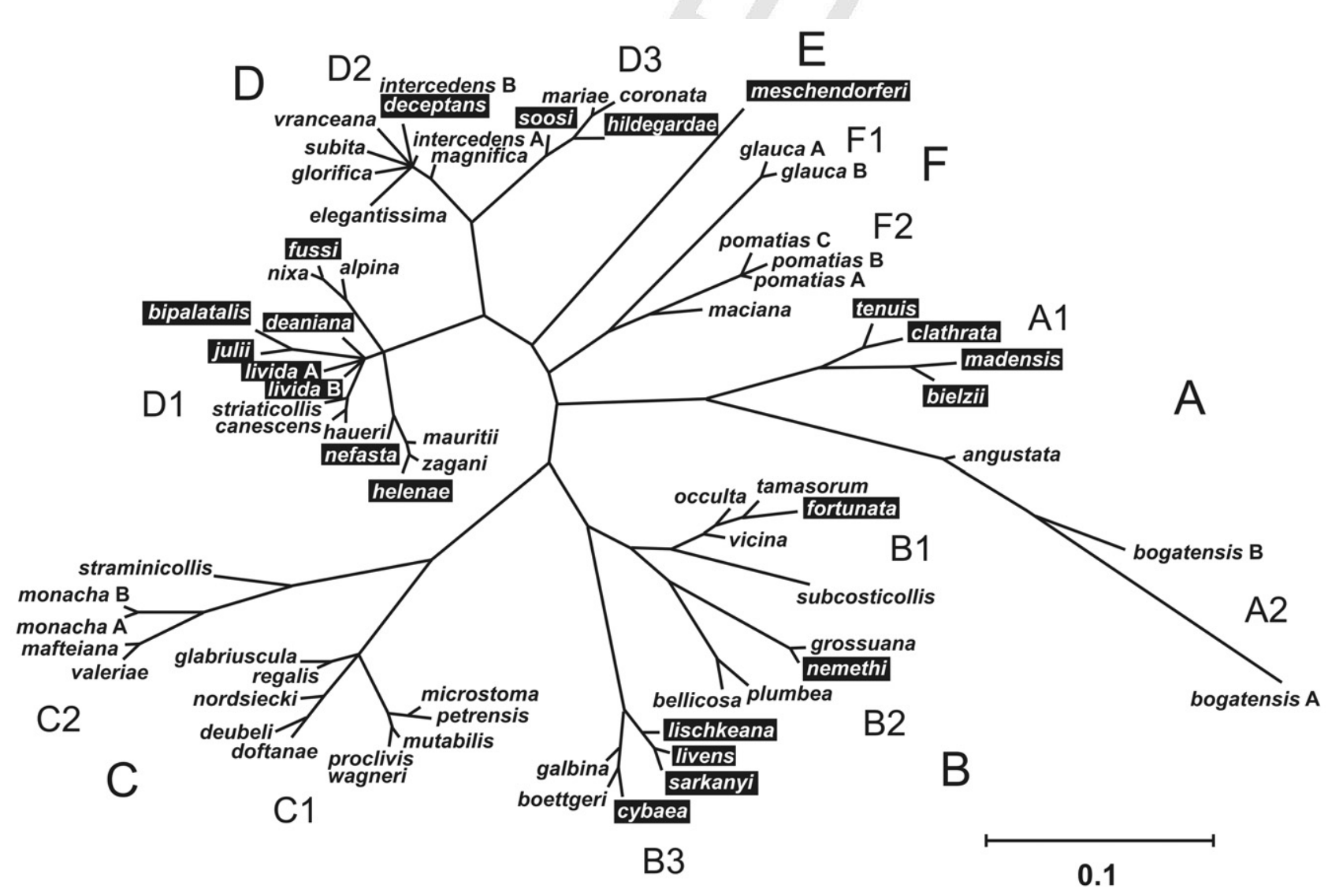

Figure 2. Unrooted phylogenetic tree inferred from Alopia COI sequences by unconstrained Bayesian analysis. Sequences are identified with the subspecific names of the sinistral (normal print) or dextral (inverted print) taxa of their origin (see Table 1). Major clades are marked with upper case letters and numbering. The sequences labelled proclivis and

[39] wagneri (clade C1), as well as intercedens (2lade B) and deceptans (clade D3), belong to identical haplotypes. Scale bar: 0.1 substitutions per site. 
Carlo (MCMC) analysis run for $10^{6}$ generations; trees sampled every 100 generations, starting after a burn-in of $10^{5}$ generations. Neighbor-joining (NJ), maximum likelihood (ML) and maximum parsimony (MP) analyses were performed with MEGA 5.0. For ML analysis we used the $\mathrm{HKY}+\mathrm{I}+\mathrm{G}$ model of sequence evolution with five gamma rate categories and the nearest-neighbor interchange heuristic search strategy. The MP tree analysis was performed using the close-neighbor interchange heuristic search strategy with random additions to ten initial sequences. The NJ analysis was performed under the Kimura two-parameter (K2P) model of substitution. Bootstrap values of the ML, MP, and NJ analyses were calculated with 1000 bootstrap replicates.

To define the most likely rooting site, we also carried out likelihood mapping (Strimmer \& von Haeseler, 1997) as implemented in TREEPUZZLE 5.2 (Schmidt et al., 2002). This method can manage a maximum of four clusters, and therefore the unconstrained Bayesian tree (Fig. 2) was divided into three trifurcation-separated subgroups in six combinations, and these were analysed against the cluster of the out-groups (Herilla and Vestia). The following combinations were tested: (1) clades C/B/ $\mathrm{A}+\mathrm{D}+\mathrm{E}+\mathrm{F} /$ out-groups; (2) clades $\mathrm{C}+\mathrm{B} / \mathrm{A} / \mathrm{D}+\mathrm{E}+$ F/out-groups; (3) clades $\mathrm{A}+\mathrm{B}+\mathrm{C} / \mathrm{F} / \mathrm{E}+\mathrm{D} /$ out-groups; (4) clades $\mathrm{E} / \mathrm{D} / \mathrm{A}+\mathrm{B}+\mathrm{C}+\mathrm{F} /$ outgroups; (5) clades $\mathrm{C} 1 / \mathrm{C} 2 / \mathrm{A}+\mathrm{B}+\mathrm{D}+\mathrm{E}+\mathrm{F} /$ out-groups; and (6) A1/A2/ $\mathrm{B}+\mathrm{C}+\mathrm{D}+\mathrm{E}+\mathrm{F} /$ out-groups.

To estimate divergence times, we used a data set that included representatives of all Alopia clades and 20 additional sequences of Carinigera Möllendorff, 1873 downloaded from the GenBank database. Bayesian analyses were performed using BEAST 1.4.6 (Drummond \& Rambaut, 2007), with the following settings: $\mathrm{HKY}+\mathrm{I}+\mathrm{G}$ model of sequence evolution with five gamma rate categories, Yule tree prior, and a relaxed (uncorrelated lognormal) clock assumption. Two analyses were carried out using clock rates of 1 or $8.6 \%$ ('ucld.mean' parameters). Following a burn-in of $10^{6}$ cycles, every 1000th tree was sampled from $10^{7}$ MCMC steps. Convergence of the chains to the stationary distribution was checked by visual inspection of plotted posterior estimates using the TRACER 1.3 (Rambaut \& Drummond, 2007). The effective sample size for each parameter sampled from the MCMC analysis was always found to exceed 100. Sampled trees were annotated to a maximum clade credibility tree.

\section{USE OF TAXONOMIC NAMES}

Recent concepts of Alopia classification (Grossu, 1981; Szekeres, 2007; Nordsieck, 2008) have been based on conflicting principles, and none of them is in full agreement with our results. A comprehensive systematic revision of the genus is beyond the scope of the present study, and will be provided in a follow-up taxonomic publication. Nevertheless, based on our results we make taxonomic statements when this is essential for the consistency of the classification that we use. For easy comparison, our names and an assessment of earlier taxonomic nomenclature are provided in Appendix S1.

\section{RESULTS}

\section{COI PHYLOGENY IN THE GENUS ALOPIA}

The $C O I$ gene sequences were determined from 71 Alopia samples (Table 1) belonging to 69 haplotypes. Within the amplified 655-bp region we identified 206 variable positions, corresponding to $31.4 \%$ of the nucleotides. The highest observed intrageneric value of pairwise sequence divergence was $13.0 \%$. Most of the detected variability had no effect on the deduced amino acid sequence, except those at nucleotide position 470, causing the replacement of proline by alanine or serine in 11 haplotypes, and unique mutations at positions 167, 315, 358, 360, 470, 480, and 525 , leading to amino acid substitutions in seven distinct haplotypes.

An unconstrained Bayesian tree generated from the COI sequences (Fig. 2) featured six basic evolutionary lineages (clades A-F). Supporting posterior probability values of the node positions are given in Appendix S2. All inference methods used (also including $\mathrm{ML}, \mathrm{MP}$, and NJ) yielded congruent topologies within the basic clades (data not shown) and nearly identical relative positions for the major clades (Appendix S2). By contrast, these methods failed to identify a consistent root position relative to the out-groups. Furthermore, likelihood mapping determined two, almost equally likely root positions that did not match any of those assigned by the above inference analyses (Appendix S3).

A recent analysis of the molecular evolution of mitochondrial genes in beetles (Pons et al., 2010) revealed an overall $8.6 \%$ per million years (Myr) divergence rate for the $C O I$ sequences. Based on this clock rate, which is similar to that determined for salamander species (Mueller, 2006), our Bayesian analysis using an uncorrelated lognormal relaxed clock model estimated the divergence of the major Alopia clades at 1.2 Mya, with a $95 \%$ highest posterior density (HPD) interval of 1.6-0.8 Myr (for details, see Appendix S4).

\section{Speciation in ALOPIA INVOLVED MUltiple INVERSIONS OF CHIRALITY}

The COI-based phylogram shows differential representation of the sinistral and dextral taxa in the 


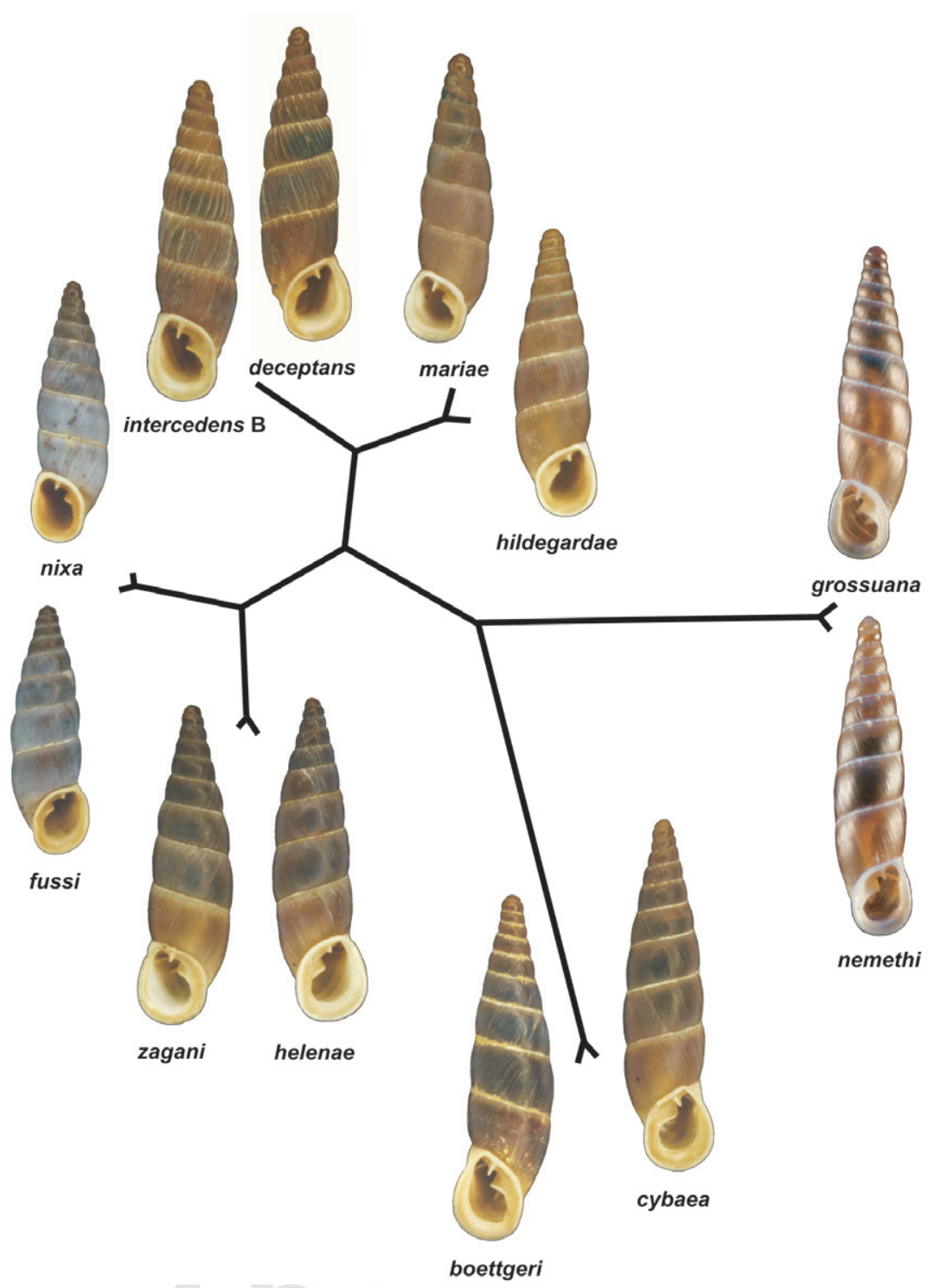

Figure 3. Shell morphology and COI-based phylogenetic relationships of the enantiomorph taxon pairs. The schematic tree follows the topology of the phylogram shown in Figure 2.

major evolutionary lineages (Fig. 2). Clades C and F comprise only sinistral taxa, whereas clade E includes

9 only the dextral taxon Alopia meschendorferi (Bielz, 1858). By contrast, clades B and D contain multiple closely related taxa with both coil directions, including all enantiomorph taxon pairs. In clade $\mathrm{A}$ the two subgroups A1 and A2 correspond to the invariably

[10] dextral Alopia bielzii (Pfeiffer, 1848) and sinistral Alopia bogatensis (Bielz, 1856) forms, respectively.

An intriguing result of the molecular phylogenetic analysis was that it revealed very high levels of sequence identity between the enantiomorph taxa Alopia glorifica deceptans Deli \& Szekeres, 2011 and Alopia glorifica intercedens (Schmidt, 1857) (100\%),
Alopia lischkeana boettgeri, Alopia lischkeana cybaea (*n-Kimakowicz, 1894), Alopia nefasta helenae Kimakowicz, 1928, Alopia nefasta zagani, Alopia nixa fussi (-Kimakowicz, 1894), and Alopia nixa nixa (von-Kimakowicz, 1894) (99.8\%), Alopia grossuana grossuana and Alopia grossuana nemethi Deli \& Szekeres, 2011 (99.6\%), as well as Alopia mariae hildegardae and Alopia mariae mariae (98.6\%). These data indicate close evolutionary relationships within these taxon pairs of opposite chirality but otherwise identical morphology (Fig. 3).

The COI-based phylogram implies that the dextral taxa did not evolve as a monophyletic lineage that stemmed from an inversion early in Alopia phylogeny. 
Instead, they appeared polyphyletically as the results of several independent inversions, rendering dextral coiling a homoplastic trait in this genus. The dextral lineages of $A$. bielzii (clade A1) and A. meschendorferi (clade E) show deep divergence (Fig. 2), whereas some others reveal only minor or no changes of the COI sequence relative to the closest related sinistral taxa.

\section{COI PHYLOGENY ELUCIDATES EVOLUTIONARY RELATIONSHIPS}

We found that clusters of the COI phylogram show good correspondence with some of the morphological traits shared by subspecies that have been classified within the same species or species assigned to species groups, especially when these characters have been considered unique for those taxa. Such features are, for instance, the rugose shell wall of A. bielzii (clade A1), the characteristic lump behind the peristome of A. bogatensis (clade A2), or the elongated 20 male genital structures of Alopia glauca (Bielz, 1853), Alopia maciana Bădărău \& Szekeres, 2001, and Alopia pomatias (Pfeiffer, 1865), which constitute the subgenus Alopia (Kimakowiczia) Szekeres, 1969 (clade F). The correlation between the molecular clade positions of the subspecies and species with their shared morphological characters and geographical ranges is shown in Appendix S5.

The molecular data also revealed hitherto unrecognized phylogenetic relationships between Alopia forms separated by large geographical distances. The results indicated that the subspecies vranceana belongs to clade D2, corresponding to the species A. glorifica, despite the $110 \mathrm{~km}$ that separates it from the Piatra Craiului Mountains where all other glorifica subspecies are limited (Fig. 1, localities 21 versus 15-20). Likewise, in clade $\mathrm{C} 1$ the subspecies microstoma, nordsiecki, and petrensis cluster together with the morphologically very similar subspecies. regalis (clade C1), although the aforementioned three taxa were traditionally classified with other species (Appendix S1) because of their occurrence 120 $190 \mathrm{~km}$ west of the Postăvaru and Piatra Mare Moun-

[2] tains, the diversity centre of Alopia regalis (Fig. 1, localities 59,61, and 62 versus 58,60,63, 64, and 65). Furthermore, the $C O I$ phylogram justifies the classification of the subspecies julii of central Transylvania [22 within the species Alopia livida (Menke, 1828) (Soós, 1943; Grossu, 1981; Nordsieck, 2008), as opposed to that of Wagner (1914) and Szekeres (1976), assuming that the striking shell similarity of julii and livida (clade D1), occurring $170 \mathrm{~km}$ apart (Fig. 1, localities 32 versus 31,33, and 34), resulted from the convergent reduction of distinctive shell structures.

Sequence data also necessitate synonymizing the forms Alopia-peregrina Kimakowicz, 1943 of the
Lotru Mountains (Fig. 1, locality 44) and Alopia-soosiana Agócsy \& Pócs, 1961 (Fig. 1, locality 55) of the Făgăraş Mountains (Table 1), which used to be considered valid taxa (Szekeres, 1976; Grossu, 1981; Nordsieck, 2008). The extensive COI homology and the apparent morphological correspondence reveal that these Alopia forms are merely disjunct populations of Alopia monacha (Kimakowicz, 1894) (99.6\% identical with peregrina) and A. pomatias (99.8\% identical with soosiana) that are native to the Bucegi Mountains.

Although COI data elucidated phylogenetic relationships, they also revealed distinct origins of certain taxa with similar shell morphology and overlapping distribution. Although originally the Alopia forms from the Postăvaru and Piatra Mare mountains were divided as subspecies of Alopia plumbea (Rossmässler, 1839) or A. regalis (Kimakowiez, 1894; Soés, 1943), respectively, later the morphological similarity lead to merging all of these within A. plumbea (Szekeres, 1976; Grossu, 1981; Nordsieck, 2008). Our molecular phylogram, however, indicates that the subspecies formerly belonging to A. plumbea (bellicosa and plumbea in clade $\mathrm{B} 2$ ) and those of $A$. regalis (deubeli, glabriuscula, mutabilis, proclivis, regalis, and wagneri in clade $\mathrm{C} 1$ ) represent two distinct evolutionary lineages. In another case, morphologically similar Alopia taxa of the Piatra Craiului Mountains were found to harbour two distinct types of $C O I$ sequences. This implies that the subspecies belonging to clades B3 (A. lischkeana) and D2 (A. glorifica) evolved independently.

\section{DISCUSSION}

The 655-bp segment of the COI sequence, which has been widely used for inferring phylogenetic information in various animal groups, represents one of the best-studied molecular markers in the subfamily Alopiinae. In Alopia the COI phylogenies deduced by various methods gave consistent topologies within each of the major clades, indicating that the analysed sequence information was sufficient for reliable reconstruction of the evolutionary relationships (Nguyen, Gesell \& Haeseler, 2012). Tree topologies in taxonomically unambiguous groups (e.g. clades A and F) were in full agreement with the morphology-based classification; therefore, we assumed similar good agreement between the COI phylogeny and speciation in groups with less distinctive morphological features. Accordingly, the taxonomic division we propose is based on the evaluation of both molecular data and morphological characters, relying on the same principle as applied for defining the systematic status of Carinigera species (Gittenberger \& Uit de Weerd, 2006). 
When correlating $C O I$ clade positions with shared morphological traits and common patterns of geographical distribution (Appendix S5), the taxonomic positions in two cases proposed here seem to require further clarification. One is the subgenus Alopia (Kimakowiczia), which includes three species (clade F) showing shell and genital structures that markedly differ from those of other Alopia groups (Bădărău \& Szekeres, 2001). But, despite the unique morphology, the subgeneric separation of this group is not supported by the COI phylogeny, which shows the same depth of divergence for the Alopia (Kimakowiczia) group as for the other major clades of the genus (Fig. 2). In the second case, the relationship between A. glorifica and A. lischkeana, both native to the Piatra Craiului Mountains, requires better insight. Although COI sequences suggest only a distant relationship between these species, their morphological similarity raises the question whether indeed they are of distinct origin, with nuclear genes showing similar descent as that of $C O I$. Addressing these questions will require further molecular phylogenetic studies, involving both nuclear and mitochondrial DNA sequences.

Unlike close evolutionary relationships, the topology of the major clades had relatively weak support in the COI phylogram (Appendix S2). A similar result was obtained by Uit de Weerd, Piel \& Gittenberger (2004), who found that in four Alopiinae genera nuclear DNA segments showed greater support for deeper nodes than $C O I$ and other mitochondrial [25] sequences. Uit de Weerd et al. (2004) proposed that for genes with a high divergence rate (Pons et al., 2010), this might result from a saturation effect. But in Alopia, COI sequences show only modest (up to $13.0 \%$ ) maximum intrageneric pairwise divergence, so saturation alone cannot explain the weaker resolution of deep branching points and the ambiguous root

26] position. We therefore interpret these as likely consequences of radiation: a lineage-splitting burst within a relatively short period of time (Wilke et al., 2010) that might have happened early during the diversification of the genus.

The only available fossil finds of Alopia were recovered from non-layered cave deposits of the Holocene period (Ložek, 1964; Szekeres, 2007). In the absence of dated fossils we calculated the divergence time of the main Alopia clades on the basis of the $8.6 \%$ per Myr COI clock rate determined in beetles (Pons et al., 2010), considering that an appropriate choice of this parameter can lead to realistic estimates even when geological calibration is not possible (Wilke, Schultheiss \& Albrecht, 2009). With the application of this rate the divergence time was placed at about 1.2 Mya, much more recently than the roughly 10.4 Mya calculated with the canonical $\sim 1 \%$ rate used previously for mitochondrial DNA sequences
(Wilke et al., 2009; Appendix S4). As a group of southeast Mediterranean origin, the ancestors of Alopia could have colonized the Carpathians via the land contact formed between the Southern Carpathians and the Balkan Mountains, disrupting the continuity of the receding Paratethys. This geological transformation took place around the Pliocene-Pleistocene boundary, dated to 2.6 Mya (Olteanu \& Jipa, 2006; Andreescu et al., 2011), suggesting that the appearance and expansion of Alopia must be more recent events. This assumption is in line with the lack of Alopia in the Early Pleistocene cave deposits of the Şprenghi Hill at Braşov (Soós, 1916), and also with the Late Pleistocene dating of fossil Mastus venerabilis (Pfeiffer 1 1855), a species of the Enidae arriving at the Carpathians from the same direction, and preferring the same habitats as Alopia, found in loess samples of south-eastern Hungary (Soós, 1943). The modest (13.0\%) intrageneric pairwise divergence of $C O I$ sequences in Alopia, as compared with those of the Balkan genera Albinaria Vest, 1867 (18.2\%), Carinigera (19.9\%) and Inchoatia Gittenberger \& Uit de Weerd, 2006 (17.8\%), also implies that this is a relatively young genus in the Alopiinae. Accordingly, the $8.6 \%$ clock rate-based $1.2 \mathrm{Mya}$ dating of early Alopia divergence, placing this event at the middle of the Pleistocene, appears to be a realistic estimate.

Mountains of the Southern and southernmost Eastern Carpathians were colonized by Alopia from different directions, leading to the presence of more than one abundant species in the Piatra Craiului (A. glorifica and A. lischkeana), Bucegi (A. livida and A. monacha), and Ciucaş [Alopia canescens (Charpentier, 1852) and $A_{2}$ nefastal ranges. These examples show that although infraspecific differentiation was usually confined to a particular mountain, co-occurrence in the same mountain does not necessarily mean close phylogenetic relationship. Though the current distribution of Alopia species seems to have been formed mostly by waves of gradual range expansion, disjunct occurrences (e.g. those shown in Fig. 4) also indicate a role for passive long-range dispersal, possibly mediated by birds (Uit de Weerd et al., 2005; Maciorowski, Urbańska \& Gierszal, 2012).

Because of their rock-dwelling character, Alopia species tend to be highly endemic, often divided within the same mountain complex into locally isolated subspecies (Soós, 1928). But the present distribution of certain groups reveals multiple waves of range expansion, which were probably facilitated by major climatic changes in the Late Pleistocene. For instance, the massive westwards expansion of alpine A. livida could have been possible during a cold period, whereas its displacement by thermophilic 


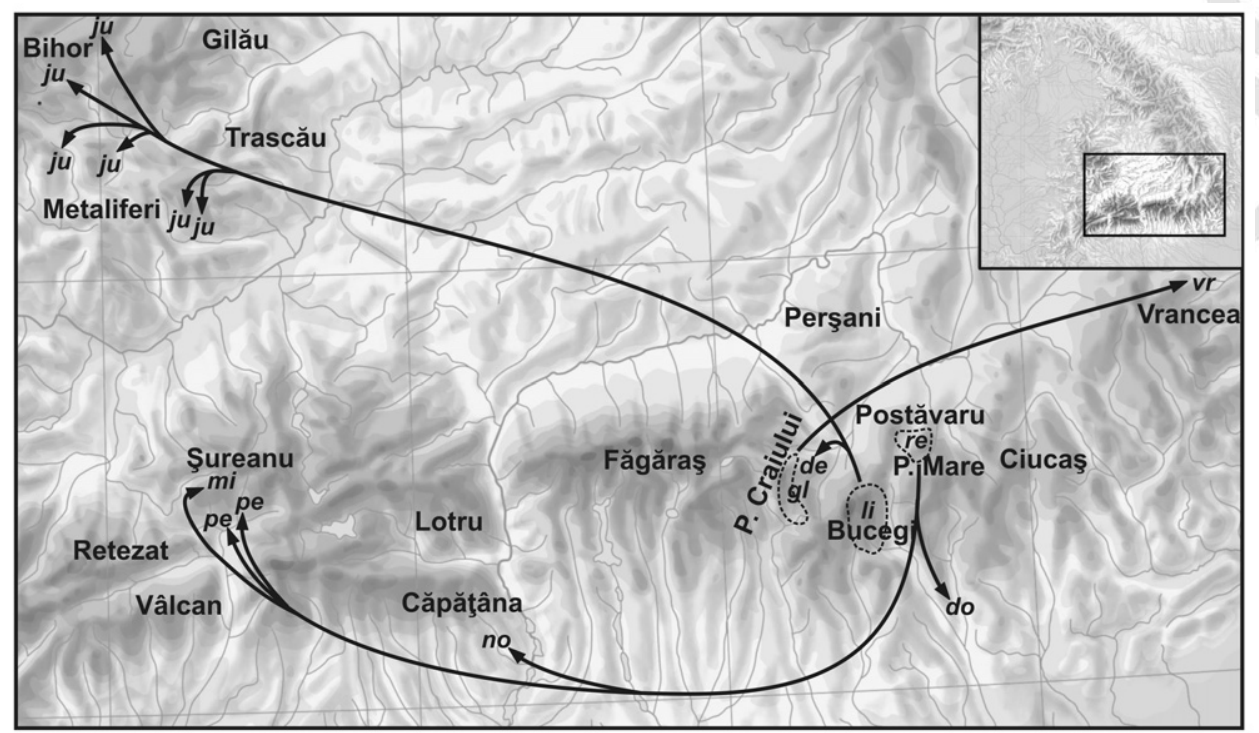

Figure 4. Alopia species of disjunct distribution. Main ranges (encircled by broken lines) and isolated occurrences of Alopia glorifica, Alopia livida, and Alopia regalis forms. Symbols correspond to A. glorifica subspecies of the Piatra Craiului Mountains (gl), A. g. vranceana (vr), A. livida subspecies of the Bucegi Mountains (li), A. l. deaniana (de), A. $l$. julii (ju), A. regalis subspecies of the Piatra Mare and Postăvaru Mountains (re), A. r. doftanae (do), A. r. microstoma (mi), A. $r$. nordsiecki (no), and A. r. petrensis (pe). Arrows show the assumed directions of range expansion. Major mountains are identified.

A. bielzii over much of its range in the BihorVlădeasa, Metaliferi, and Trascău mountains (Fig. 4) must have taken place at stages of warmer climate. Likewise, cooler periods could have been favourable for the wide distribution of the cold-hardy species of clade $\mathrm{F}$, whereas during subsequent warming their habitats became fragmented and, in the cases of A. maciana and A. pomatias, increasingly overtaken by more thermotolerant A. bielzii and A. livida, respectively. Disjunct occurrences of four A. regalis subspecies, far away from the main range of the species in the Piatra Mare Mountains, also attests to an earlier westwards expansion (Fig. 4).

In the exposed limestone habitats, climatic cycles could have had a substantial influence on diversification (Scheel \& Hausdorf, 2012). Range expansions at favourable periods were followed by the breaking-up of the ranges during epochs of harsher climate. This led to the severe reduction of population sizes, as seen today in the case of alpine A. pomatias and of some species or subspecies occurring at low (below 1000 m a.s.l.) altitudes (Bădărău \& Szekeres, 2001; Szekeres, 2007). Colonization by passive dispersal, a common method of radiation among rock-dwelling snails, also generated very small populations. In such cases unbalanced gene pools result in increased phenotypic variability, which can lead to multiple local forms within relatively short periods of time (Gitten- berger, 1991; Rundell \& Price, 2009). Such genetic drift effects may be behind the apparent discrepancy between the more diverse morphological traits in Alopia and the less diverse indispensable COI genes, compared with other genera of the Alopiinae.

Speciation in Alopia is further enhanced by an increased tendency for chiral reversal. The anatomical difference between the individuals of opposite coiling considerably restricts interchiral mating, thereby leading to reproductive isolation and, in most cases, selection-based disappearance of reversed snails in the population (Gittenberger, 1988; Asami, Cowie \& Ohbayashi, 1998). But because of the relatively high frequency of inversions in this genus, occasionally such individuals of the same offspring succeed in establishing stable subpopulations, a process facilitated by the low dispersal rate of rock-dwelling snails (Schilthuizen \& Lombaerts, 1994). As the reproductive success of each chiral morph is ensured by the availability of surrounding mating partners of the same chirality, this gradually leads to territorial separation and, in time, the formation of isolated sinistral and dextral populations (Ueshima \& Asami, 2003). At this level of speciation, exemplified by the enantiomoph pairs of Alopia, further gene flow between neighbouring populations of the opposite chiral forms is severely restricted (Schilthuizen \& Lombaerts, 1994). With their clearly different morphology and reproductive 
isolation they represent divergent evolutionary lineages, and can be regarded as distinct subspecies.

Our molecular phylogenetic study revealed that dextral taxa of Alopia did not evolve monophyletically, but via multiple independent inversions. Although the establishment and stabilization of reversed populations happened rarely, this was much more common than in any other genera of clausiliids (Gittenberger, Hamann \& Asami, 2012). Based on the COI tree (Fig. 2) we calculate that, considering a parsimonious scenario of only sinistral to dextral inversions, chirality changes gave rise to new phylogenetic lineages on at least 13 occasions during the evolution of the genus. This clearly indicates the decreased stability of chiral fixation in the species of clades B and D. Because of this unique feature and the availability of enantiomorph pairs, these Alopia taxa can become valuable subjects of genetic studies aimed at clarifying the molecular background of chiral determination and its fixation.

\section{ACKNOWLEDGEMENTS}

The authors are thankful to Gheorghe Ban, Edmund Gittenberger, Bas Kokshoorn, Harry G. Lee, Mariana Pascu, Endre Sárkány-Kiss, Ioan Sîrbu, and Dennis R. Uit de Weerd for their support and valuable discussions, Tamás Deli, Tamás Domokos, Zoltán Erôss, András Hunyadi, Kornél Kovács, Barna Páll-Gergely, Péter Subai, and Cătălina Trif for their help with fieldwork, and to two anonymous reviewers for their helpful comments. Z.F. was supported by the Hungarian Scientific Research Fund (OTKA-NNF 78185) and a János Bolyai Research Scholarship of the Hungarian Academy of Sciences.

\section{REFERENCES}

Andreescu I, Codrea V, Enache C, Lubenescu V, Munteanu T, Petculescu A, Stuica E, Terzea E. 2011. Reassessment of the Pliocene/Pleistocene (Neogene/ Quaternary) boundary in the Dacian Basin (Eastern Paratethys), Romania. Oltenia, Ştudii şi Comunicări. Ştiinţele Naturii 27: 197-220.

Asami T, Cowie RH, Ohbayashi K. 1998. Evolution of mirror images by sexually asymmetric mating behavior in hermaphroditic snails. American Naturalist 152: 225236.

Asami T, Gittenberger E, Falkner G. 2008. Whole-body enantiomorphy and maternal inheritance of chiral reversal in the pond snail Lymnaea stagnalis. Journal of Heredity 99: $552-557$.

Bădărău AS, Szekeres M. 2001. Alopia (Kimakowiczia) maciana n. sp., a Pleistocene relict of the Gilău-Muntele Mare Mts. in Romania. Archiv für Molluskenkunde 129: $65-68$.
Bielz EA. 1861. Vorarbeiten zu einer Fauna der Land- und Süsswasser-Mollusken Siebenbürgens. Verhandlungen und Mitteilungen des Siebenbürgischen Vereins für Naturwissenschaften zu Hermannstadt 12: 83-100, 115-116, 131-132, 146-148, 163-164, 176-179.

Crampton HE. 1894. Reversal of cleavage in a sinistral gastropod. Annals of the New York Academy of Sciences 8: 167-170.

Davison A, Chiba S, Barton NH, Clarke B. 2005. Speciation and gene flow between snails of opposite chirality. PLoS Biology 3: e282.

Degner E. 1952. Der Erbgang der Inversion bei Laciniaria biplicata MTG. (Gastr. Pulm.). Mitteilungen aus dem Hamburgischen Museum und Institut 51: 3-61.

Douris V, Gameron RAD, Rodakis GG, Leeanidou-R. 1998. Mitochondrial phylogeography of the land snail $A l b i$ naria in Crete: long term geologieal and-short term vieariance effects. Evolution 52: 116 125.

Drummond AJ, Rambaut A. 2007. BEAST: Bayesian evolutionary analysis by sampling trees. BMC Evolutionary Biology 7: 214.

Fehér Z, Szabó K, Bozsó M, Pénzes Z. 2009. Phylogeny and phylogeography of the Lozekia-Kovacsia species group (Gastropoda: Hygromiidae). Journal of Zoological Systematics and Evolutionary Research 47: 306-314.

Gittenberger E. 1988. Sympatric speciation in snails, a largely neglected model. Evolution 42: 826-828.

Gittenberger E. 1991. What about non-adaptive radiation? Biological Journal of the Linnean Society 43: 263-272.

Gittenberger E, Hamann TD, Asami T. 2012. Chiral speciation in terrestrial pulmonate snails. PLoS ONE 7: e34005.

Gittenberger E, Piel WH, Groenenberg D. 2004. The Pleistocene glaciations and the evolutionary history of the polytypic snail species Arianta arbustorum (Gastropoda, Pulmonata, Helicidae). Molecular Phylogenetics and Evolution 30: 64-73.

Gittenberger E, Uit de Weerd DR. 2006. Reconsidering the generic position of the species once classified in Carinigera, Isabellaria and Sericata (Gastropoda, Pulmonata, Clausiliidae, Alopiinae). Basteria 70: 57-66.

Grossu AV. 1981. Gastropoda Romaniae, 3. Suprafamilile Clausiliacea şi Achatinacea. Bucharest: Univrsitatea din Bucureşti.

Guindon S, Gascuel O. 2003. A simple, fast, and accurate algorithm to estimate large phylogenies by maximum likelihood. Systematic Biology 52: 696-704.

Hatzoglou E, Rodakis GC, Lecanidou R. 1995. Complete sequence and gene organization of the mitochondrial genome of the land snail Albinaria coerulea. Genetics 140: $1353-1366$.

Hebert PDN, Cywinska A, Ball SL, deWaard JR. 2003. Biological identifications through DNA barcodes. Proceedings of the Royal Society of London B 270: 313321.

Hoso M, Asami T, Hori M. 2007. Right-handed snakes: convergent evolution of asymmetry for functional specialization. Biology Letters 3: 169-172. 
Kimakowicz M. 1894. Prodromus zu einer Monographie des Clausilia-Subgenus Alopia H. et A. Adams. Verhandlungen und Mitteilungen des Siebenbürgischen Vereins für Naturwissenschaften zu Hermannstadt 43: 19-58.

Kuroda R, Endo B, Abe M, Shimizu M. 2009. Chiral blastomere arrangement dictates zygotic left-right asymmetry pathway in snails. Nature 462: 790-794.

Ložek V. 1964. Quartärmollusken der Tschechoslowakei. Praha: Československá Akademie Věd.

Maciorowski G, Urbańska M, Gierszal H. 2012. An example of passive dispersal of land snails by birds - short note. Folia Malacologica 20: 139-141.

Mueller RL. 2006. Evolutionary rates, divergence dates, and the performance of mitochondrial genes in Bayesian phylogenetic analysis. Systematic Biology 55: 289-300.

Nguyen MAT, Gesell T, Haeseler A. 2012. ImOSM: intermittent evolution and robustness of phylogenetic methods. Molecular Biology and Evolution 29: 663-673.

Nordsieck H. 2007. Worldwide door snails. Hackenheim: ConchBooks.

Nordsieck H. 2008. The system of the genus Alopia H. \& A. Adams 1855 (Gastropoda: Stylommatophora: Clausiliidae). Mitteilungen der Deutschen Malakozoologischen Gesellschaft 79/80: 7-18.

Olteanu R, Jipa DC. 2006. Dacian Basin environmental evolution during upper Neogene within the Paratethys domain. Geo-Eco-Marina 12: 91-105.

Pons J, Ribera I, Bertranpetit J, Balke M. 2010. Nucleotide substitution rates for the full set of mitochondrial protein-coding genes in Coleoptera. Molecular Phylogenetics and Evolution 56: 796-807.

Posada D. 2008. jModelTest: phylogenetic model averaging. Molecular Biology and Evolution 25: 1253-1256.

Rambaut A, Drummond AJ. 2007. Tracer v1.5. Available at: http://beast.bio.ed.ac.uk/Tracer (accessed January, 2012).

Ronquist F, Teslenko M, van der Mark P, Ayres D, Darling A, Höhna S, Larget B, Liu L, Suchard MA, Huelsenbeck JP. 2012. MrBayes 3.2: efficient Bayesian phylogenetic inference and model choice across a large model space. Systematic Biology 61: 170-173.

Rundell RJ, Price TD. 2009. Adaptive radiation, nonadaptive radiation, ecological speciation and nonecological speciation. Trends in Ecology and Evolution 24: 394-399.

Scheel BM, Hausdorf B. 2012. Survival and differentiation of subspecies of the land snail Charpentieria itala in mountain refuges in the Southern Alps. Molecular Ecology 21: 3794-3808.

Schilthuizen M, Lombaerts M. 1994. Population structure and levels of gene flow in the Mediterranean land snail Albinaria corrugata (Pulmonata: Clausiliidae). Evolution 48: 577-586.

Schmidt HA, Strimmer K, Vingron M, von Haeseler A. 2002. TREE-PUZZLE: maximum likelihood phylogenetic analysis using quartets and parallel computing. Bioinformatics 18: 502-504.
Shibazaki Y, Shimizu M, Kuroda R. 2004. Body handedness is directed by genetically determined cytoskeletal dynamics in the early embryo. Current Biology 14: 14621467.

Soós L. 1916. A brassói Fortyogó-hegy praeglaciális csigafaunájáról - Die präglaziale Molluskenfauna des Fortyogóberges bei Brassó. Barlangkutatás 4: 141-150. 189-196.

Soós L. 1928. Az Alopia nem. - The genus Alopia. Annales Musei Nationalis Hungarici 25: 261-426.

Soós L. 1943. A Kárpát-medence Mollusca-faunája (Mollusca fauna of the Carpathian Basin). Budapest: Akadémiai Kiadó.

Strimmer K, von Haeseler A. 1997. Likelihood-mapping: a simple method to visualize phylogenetic content of a sequence alignment. Proceedings of the National Academy of Sciences of the United States of America 94: 6815-6819.

Sturtevant AH. 1923. Inheritance of direction of coiling in Lymnaea. Science 58: 269-270.

Szekeres M. 1976. New aspects of an Alopia-system. Acta Zoologica Academiae Scientiarum Hungaricae 22: 389396.

Szekeres M. 2007. Four new subspecies of Alopia H. \& A. Adams 1855 (Gastropoda, Pulmonata: Clausiliidae). Schriften zur Malakozoologie 23: 7-18.

Tamura K, Peterson D, Peterson N, Stecher G, Nei M, Kumar S. 2011. MEGA5: molecular evolutionary genetics analysis using maximum likelihood, evolutionary distance, and maximum parsimony methods. Molecular Biology and Evolution 28: 2731-2739.

Ueshima R, Asami T. 2003. Evolution: single-gene speciation by left-right reversal. Nature 425: 679 .

Uit de Weerd DR, Piel WH, Gittenberger E. 2004. Widespread polyphyly among Alopiinae snail genera: when phylogeny mirrors biogeography more closely than morphology. Molecular Phylogenetics and Evolution 33: 533-548.

Uit de Weerd DR, Schneider D, Gittenberger E. 2005. The provenance of the Greek land snail species Isabellaria pharsalica: molecular evidence of recent passive longdistance dispersal. Journal of Biogeography 32: 1571-1581.

Uit de Weerd DR, Schneider D, Gittenberger E. 2009. Molecular phylogenetic relationships of Inchoatia taxa. Zoologische Mededelingen 83: 589-592.

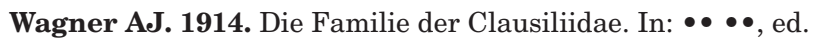
Rossmässler's Iconographie der Land- und Süsswassermollusken. Wiesbaden: Kreidel, 21.

Wilke T, Benke M, Brändle M, Albrecht C, Bichain JM. 2010. The neglected side of the coin: non-adaptive radiations in spring snails (Bythinella spp.). In: Glaubrecht M, ed. Evolution in action. Case studies in adaptive radiation, speciation and the origin of biodiversity. Dordrecht: Springer, 551-578.

Wilke T, Schultheiss R, Albrecht C. 2009. As time goes by: a simple fool's guide to molecular clock approaches in invertebrates. American Malacological Bulletin 27: 25-45. 
Additional supporting information may be found in the online version of this article:

Appendix S1. COI-based topology and nomenclatural status of the Alopia taxa studied.

Appendix S2. Branch support values of the COI clades in Alopia.

Appendix S3. Putative root positions in the COI phylogram of Alopia.

Appendix S4. Comparison of divergence times in the genera Carinigera and Alopia, based on their COI sequences.

Appendix S5. Correlations between COI topology, morphology, and geographical distribution of Alopia species. 
Required software to e-Annotate PDFs: Adobe Acrobat Professional or Adobe Reader (version 8.0 or above). (Note that this document uses screenshots from Adobe Reader $\mathrm{X}$ )

The latest version of Acrobat Reader can be downloaded for free at: http://get.adobe.com/reader/

Once you have Acrobat Reader open on your computer, click on the Comment tab at the right of the toolbar:

닙

This will open up a panel down the right side of the document. The majority of tools you will use for annotating your proof will be in the Annotations section, pictured opposite. We've picked out some of these tools below:

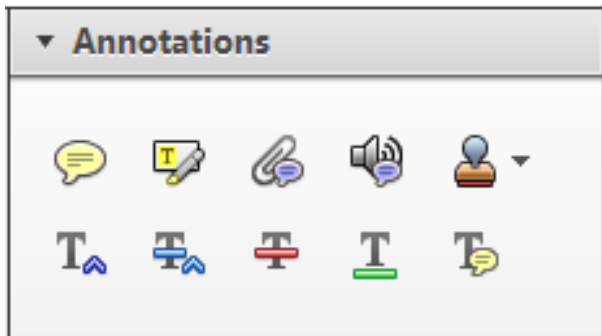

1. Replace (Ins) Tool - for replacing text.

Strikes a line through text and opens up a text box where replacement text can be entered.

\section{How to use it}

- Highlight a word or sentence.

- Click on the Replace (Ins) icon in the Annotations section.

- Type the replacement text into the blue box that appears.

Idard tramework for the analysis of $\mathrm{m}$ icy-Nevertheless, it also led to exog،

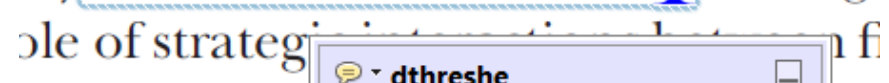
aber of comp 08/06/2011 15:58:17

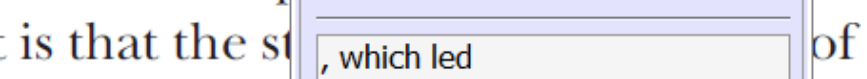
nain compo: be level, are exc nc

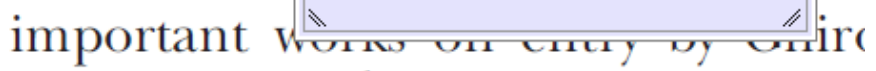
M heneferth) ${ }^{1}$ we anen the 'hlark $\mathrm{h}$

3. Add note to text Tool - for highlighting a section to be changed to bold or italic.

T Highlights text in yellow and opens up a text box where comments can be entered.

\section{How to use it}

- Highlight the relevant section of text.

- Click on the Add note to text icon in the Annotations section.

- Type instruction on what should be changed regarding the text into the yellow box that annears.

namic responses of mark ups ent with the VAR evidence

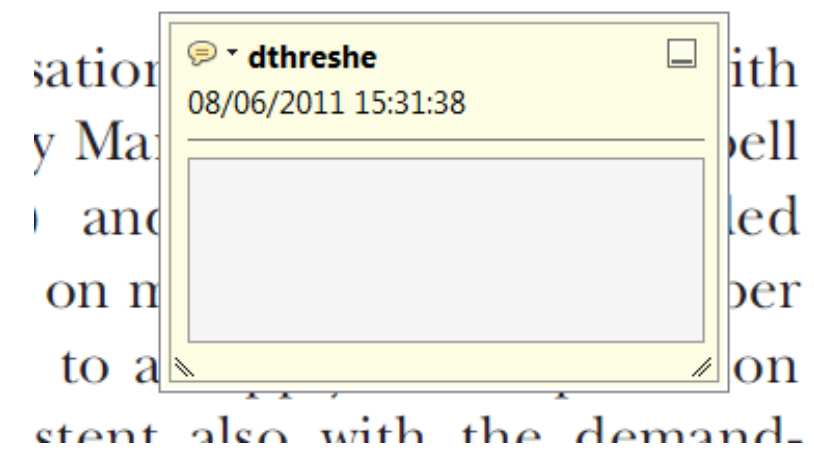

2. Strikethrough (Del) Tool - for deleting text.

Thikes a red line through text that is to be deleted.

\section{How to use it}

- Highlight a word or sentence.

- Click on the Strikethrough (Del) icon in the Annotations section.

there is no room tor extra prohts al c ups are zero and the number of ret) values are not determined by Blanchard and Kiyotaki (1987), rfect competition in general equilil ts of aggregate demand and supply lassical framework assuming monol eon an evorenois number of firms

\section{Add sticky note Tool - for making notes at} specific points in the text.

Marks a point in the proof where a comment needs to be highlighted.

\section{How to use it}

- Click on the Add sticky note icon in the Annotations section.

- Click at the point in the proof where the comment should be inserted.

- Type the comment into the yellow box that appears.

lallu allu suppiy silucks. hivst vi

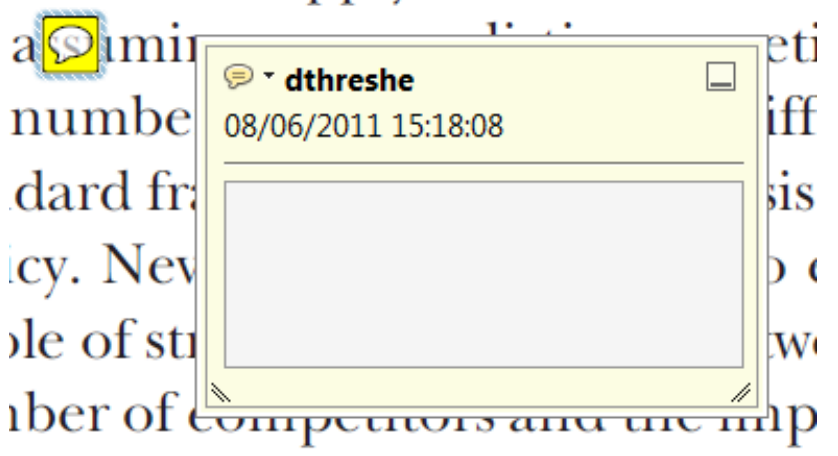

is that the structure of the secto 
5. Attach File Tool - for inserting large amounts of text or replacement figures.

Inserts an icon linking to the attached file in the appropriate pace in the text.

How to use it

- Click on the Attach File icon in the Annotations section.

- Click on the proof to where you'd like the attached file to be linked.

- Select the file to be attached from your computer or network.

- Select the colour and type of icon that will appear in the proof. Click OK.

E N D

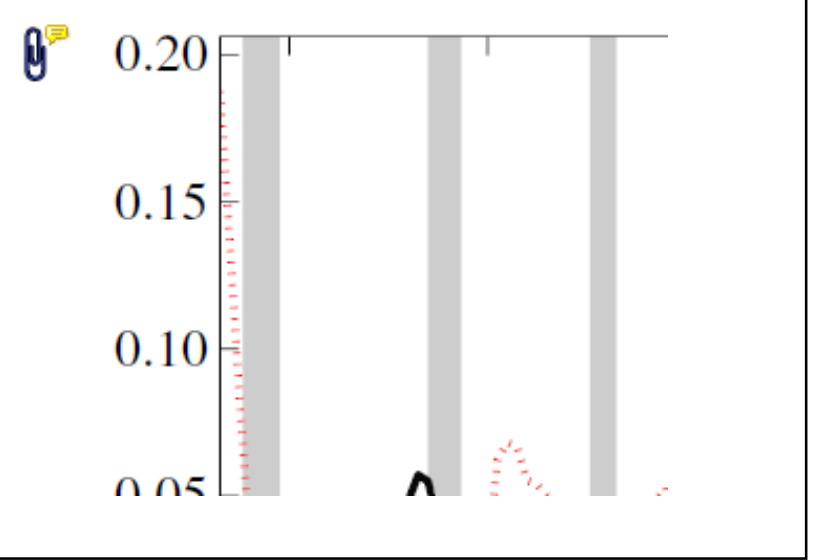

6. Add stamp Tool - for approving a proof if no corrections are required.

- Inserts a selected stamp onto an appropriate place in the proof

\section{How to use it}

- $\quad$ Click on the Add stamp icon in the Annotations section.

- $\quad$ Select the stamp you want to use. (The Approved stamp is usually available directly in the menu that appears).

- Click on the proof where you'd like the stamp to appear. (Where a proof is to be approved as it is, this would normally be on the first page).

of the Dusiness cycie, starting with the on perfect competition, constant ret

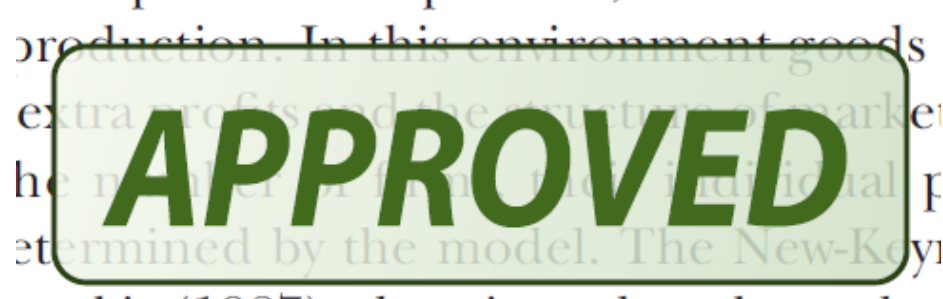

otaki (1987), has introduced produc general equilibrium models with nomin
- Drawing Markups

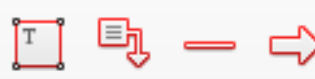

$0 \square \sqrt{6} D$

\section{How to use it}

- Click on one of the shapes in the Drawing Markups section.

- Click on the proof at the relevant point and draw the selected shape with the cursor.

- To add a comment to the drawn shape, move the cursor over the shape until an arrowhead appears.

- Double click on the shape and type any text in the red box that appears.
7. Drawing Markups Tools - for drawing shapes, lines and freeform annotations on proofs and commenting on these marks.

Allows shapes, lines and freeform annotations to be drawn on proofs and for comment to be made on these marks.

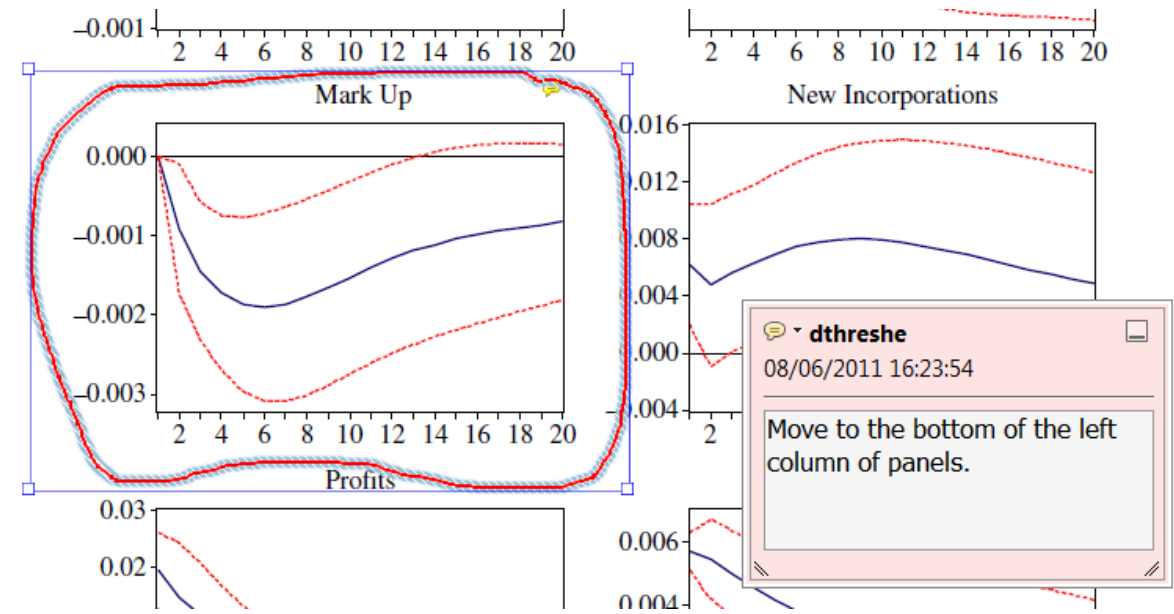

For further information on how to annotate proofs, click on the Help menu to reveal a list of further options:

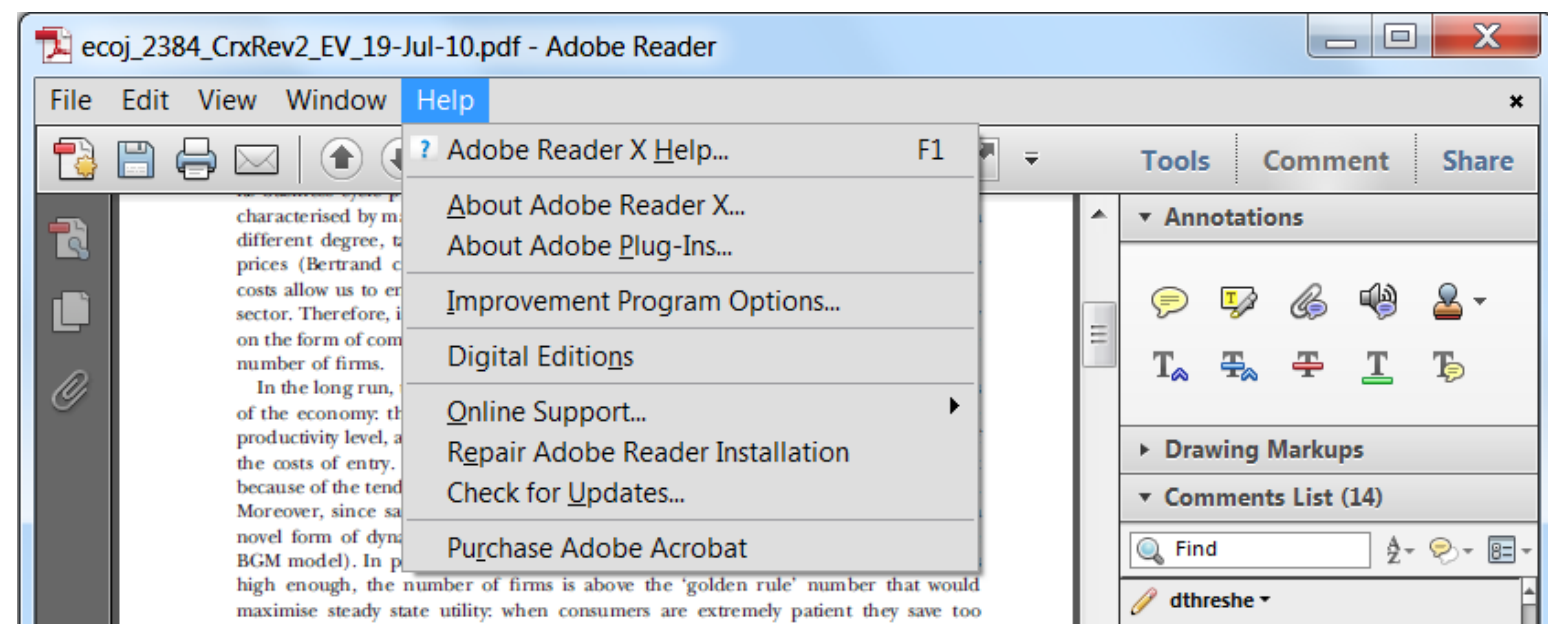

